\title{
Análisis del uso de la metáfora en el contexto de la ingeniería
}

\author{
Ana Roldán-Riejos, Universidad Politécnica de Madrid (UPM), España \\ Paloma Úbeda-Mansilla, Universidad Politécnica de Madrid, España
}

\begin{abstract}
Resumen: Diversos estudios realizados con anterioridad sobre el uso de la metáfora (Cameron and Low 1999; Cortazzi and Jin 1999; Littlemore and Low 2006; Low 1999) aseguran que la práctica pedagógica de la metáfora en el aula puede mejorar las destrezas comunicativas de los estudiantes de lenguas extranjeras. No obstante, poca atención se ha prestado hasta el momento al uso y aprendizaje de la metáfora por parte de los estudiantes de enseñanzas técnicas que a su vez aprenden inglés como lengua extranjera (Littlemore 2009). En este trabajo, se ha analizado el contenido metafórico de las respuestas proporcionadas por un grupo de estudiantes españoles de cuarto curso de ingeniería a los que se les pidió que describieran sucintamente diversas imágenes visuales de estructuras de ingeniería. Las respuestas de los estudiantes fueron a su vez cotejadas con las suministradas por diversos profesionales de la ingeniería con el fin de examinar diferencias y similitudes entre el campo académico y el profesional. Diversos estudios realizados sobre el uso de la metáfora (Cameron and Low 1999; Cortazzi and Jin 1999; Littlemore and Low 2006; Low 1999) aseguran que la práctica pedagógica de la metáfora en el aula puede servir para mejorar las destrezas comunicativas de los estudiantes de lenguas extranjeras. No obstante, poca atención se ha prestado hasta el momento al uso y aprendizaje de la metáfora por parte de los estudiantes de enseñanzas técnicas que a su vez están aprendiendo una segunda lengua, como el inglés (Littlemore 2009). En este trabajo, se ha analizado el contenido metafórico de las respuestas proporcionadas por un grupo de estudiantes españoles de cuarto curso de ingeniería a los que se les pidió que describieran sucintamente diversas imágenes visuales de estructuras de ingeniería. El marco teórico aplicado al estudio sigue la teoría de la metáfora conceptual y lingüística y de la integración conceptual (Deignan 2005, Steen 2007, Fauconnier and Turner 2002, Fauconnier and Turner 2008). Actualmente, la enseñanza curricular de estos alumnos no incluye nociones sobre el uso de la metáfora en español ni en inglés. Las respuestas de los estudiantes fueron a su vez cotejadas con las suministradas por diversos profesionales de la ingeniería con el fin de examinar diferencias y similitudes entre el campo académico y el profesional. Los resultados obtenidos revelan un uso considerable de la metáfora en los ejemplos en español recopilados de ambos grupos. De ahi que en las conclusiones, se señale la conveniencia de incluir en la formación pedagógica de los estudiantes de ingeniería el uso de la metáfora tanto en lengua original como en la lengua fuente, puesto que cada lengua hace un uso distinto que es preciso conocer de este importante recurso comunicativo.
\end{abstract}

Palabras Clave: Uso de la Metáfora en la Ingeniería, Comunicación Académica y Profesional, Aprendizaje y Didáctica del Lenguaje Técnico

Abstract: Previous studies on metaphor use (Cameron and Low 1999; Cortazzi and Jin 1999; Littlemore and Low 2006; Low 1999) claim that the pedagogic practice of metaphor in the classroom could serve to develop the comprehension and communicative skills of EFL learners. Nevertheless, the use of metaphor by technical second language learners has received little attention so far (Littlemore 2009). In this paper, the metaphorical content of the responses that a group of 4th year Spanish engineering

Revista Internacional de Educación y Aprendizaje

Volumen 1, 2013, http://sobrelaeducacion.com/revistas/coleccion/, ISSN 2255-453X

(C) Global Knowledge Academics. Ana Roldán-Riejos, Paloma Úbeda-Mansilla

Todos los Derechos Reservados. Permisos: soporte@gkacademics.com 
undergraduates gave out when asked to briefly describe visual images of engineering structures have been analysed. Currently, the academic syllabuses for engineering students in most Spanish universities lack any reference to metaphor use either in Spanish or English. The responses obtained from the students were in turn crosschecked against those given by engineers in order to compare output both in the academic and the professional fields. The results reveal a significant high frequency in metaphor use in the examples produced both by engineers and by engineering students. We thus argue about the effectiveness to include pedagogical notions about metaphor theory and metaphor use as part of the linguistic training of engineering learners. These should include differences between the first and the second language, since metaphor use varies from one language to another. The theoretical framework adopted for this work follows conceptual and metaphor theory and conceptual integration/blending findings (Deignan 2005, Steen 2007, Fauconnier and Turner 2002, Fauconnier and Turner 2008).

Keywords: Metaphor Use in Engineering, Academic and Professional Communication, Learning Technical Languag

\section{Introducción}

$\mathrm{L}$

A EXPERIENCIA, EL entorno o la formación académica pueden de alguna forma influir en la forma de comunicarse, incluyendo en la elección de palabras. De modo similar, la lengua refleja la manera en que las cosas son percibidas, clasificadas, o incluso la perspectiva del hablante. Según Littlemore (2009:13): "El lenguaje es un reflejo de la cognición general". Para referirse a este fenómeno, la lingüística cognitiva utiliza la noción de constructos. En líneas generales, los constructos se corresponden con el uso de aquellos términos más destacados y arraigados conceptualmente (Ibíd.: 15-27). Paralelamente, la percepción sensorial, la actividad motora, la interacción con el medio, así como el lenguaje, se ven influidos por las características físicas del cuerpo, de la mente y de los sentidos. Esta idea es fundamental en la teoría de la metáfora conceptual y lingüística que afirma que la metáfora es una herramienta común tanto al pensamiento como al lenguaje (Lakoff 1987, Kövecses 2005). La metáfora relaciona dos ámbitos diferentes de significado, de tal manera que uno de ellos activa correspondencias que son propias del otro. En la metáfora, los conceptos más abstractos se entienden en términos concretos y físicos. En otras palabras, los conceptos físicos actúan como dominio de origen para los conceptos abstractos del dominio de destino. Este trabajo intenta explorar el uso de la metáfora en el contexto de la ingeniería, así como otros mecanismos conexos, como puede ser la metonimia. Los objetivos perseguidos son los siguientes:

- Analizar el uso espontáneo de la metáfora contextual por estudiantes de $4^{\circ}$ curso de ingeniería civil UPM. Comparar con las respuestas proporcionadas por un grupo de ingenieros.

- Examinar ejemplos concretos de metáfora de la ingeniería civil en los planos lingüístico, conceptual y visual.

- Proponer un enfoque multimodal que aborde la metáfora en esta especialidad y sobre las preferencias conceptuales y discursivas de grupo.

En primer lugar, mostraremos el uso de la metáfora en el contexto de la ingeniería. En segundo lugar se analizan las respuestas que dieron los estudiantes de ingeniería cuando se le 
preguntó sobre cómo verbalizan sus percepciones. Los principales elementos analizados en este trabajo son:

1. El uso de la metáfora en la etapa académica de un grupo de alumnos.

2. El uso de la metáfora en la etapa profesional de un grupo de ingenieros.

3. Variación y comparación del uso de la metáfora entre los estudiantes de ingeniería y los ingenieros.

Para ello, hemos partido de investigaciones previas relacionadas con la presencia de la metáfora en diversos géneros de la ingeniería (Roldán 1999, Úbeda 2001, Roldán 2004, Roldán and Úbeda 2006, Robisco 2009). Asimismo, se han tenido en cuenta las evidencias recogidas a partir de un corpus lingüístico sobre la metáfora en la ingeniería civil. Los resultados concluyen con algunas observaciones sobre el uso de la metáfora en el dominio de la ingeniería y algunas orientaciones pedagógicas para el futuro.

\section{Marco teórico}

Los estudios existentes sobre discurso y metáfora tienden a catalogarla dentro de la lingüística general, como un tipo de lenguaje figurado (Littlemore and Low 2006, Deignan 2005), atendiendo en particular a su uso. Cameron define la metáfora lingüística como el uso de una palabra o frase que lleva o proporciona algún otro significado al significado contextual. De acuerdo con esta definición, la palabra o frase que aporta otro significado, que contrasta con el tema principal del texto, es el vehículo y el tema principal constituye el tema. Además, las expresiones metafóricas pueden ser estudiadas en su conjunto a nivel de discurso, es decir, centrándose principalmente en su función textual, según su género y cómo funcionan estas en el discurso (Roldán and Úbeda 2006). A través de los años, los estudios existentes y basados en datos en español y en inglés sobre el uso de la metáfora en la comunicación de la ingeniería se han referido principalmente a la teoría de la metáfora conceptual (Caballero 2003a y 2003b, Roldán and Úbeda 2006). Consideramos, sin embargo, que el análisis de la metáfora lingüística en su contexto podría completarse con la teoría de la integración conceptual. La teoría de la integración conceptual (blending) aborda no sólo las mezclas conceptuales ("blends"), sino también operaciones cognitivas como la categorización, los marcos ("frames"), los cambios de puntos de vista ("viewpoint shifts"), los contrafactuales ("counterfactuals"), la metáfora y la metonimia. La teoría de la integración conceptual explicaría correspondencias y constructos utilizados en la ingeniería, como se muestra más adelante. La mezcla o integración conceptual se define como una operación cognitiva capaz de combinar y crear nuevos conceptos a partir de distintos campos, "inputs", o dominios (Fauconnier and Turner 2002; Fauconnier 1997). Grady, Oakley, and Coulson (1999), en su muy citado ejemplo: 'This surgeon is a butcher' (este cirujano es un carnicero), presentan un espacio genérico que aúna las características de un cirujano (lugar de trabajo, ocupación, etc.) con las de un carnicero, surgiendo de la fusión de ambas un espacio nuevo emergente que mezcla tanto las características comunes de ambas ocupaciones con otras nuevas, en definitiva que el cirujano no es de fiar. Deignan (2005:222) señala las ventajas de un tercer espacio conceptual formado con la fusión de los dominios precedentes, en lugar de sólo el dominio de origen y el dominio de destino, como explicaba la teoría de la metáfora conceptual. La integración conceptual serviría para explicar el dinamismo de la creación de significado mediante la combinación de espacios genéricos, y la fusión de dominios fuente y de destino 
dando lugar a nuevos espacios emergentes. En ingeniería, podemos hablar de ejemplos de integración procedentes de diversos dominios de origen, que con el tiempo han ido adquiriendo sentidos innovadores (Úbeda 2001; Úbeda 2002; Roldán, Úbeda and Santiago 2011). Por ejemplo, se pueden observar aportaciones procedentes de la psicología y la medicina que se funden con las de ingeniería, dando lugar a conceptos tales como el esfuerzo, la deformación, la vulnerabilidad, la excitabilidad, la fatiga, referidos a elementos de las obras ingenieriles.

La figura 1 muestra un entrecruzamiento de dos espacios mentales que con frecuencia se dan en ingeniería y que explicamos a continuación. Los espacios mentales son una especie de paquetes dinámicos de información generados en el acto comunicativo. Fauconnier 1987: 11 se refiere literalmente a "estructuras parciales que proliferan mientras pensamos y hablamos, con el fin de dar pie a la comprensión y acción local”. Además, los espacios mentales "se construyen de forma dinámica en la memoria de trabajo, y se afianzarían en la memoria a largo plazo" (Ib.). La figura 1 representa los espacios mentales que pueden ser evocados simultáneamente mientras se discute del bienestar de las personas. Por un lado, incluiría la experiencia del hábitat más cercano, es decir, el propio cuerpo y aspectos de bienestar físico, así como elementos estéticos (por ejemplo, tener una buena figura) y, por otro lado, la experiencia de un tipo del hábitat de la vivienda que debe ser igualmente saludable. Los espacios evocados se pueden referir al bienestar de las personas que viven o visitan el edificio y comprenderían factores físicos (por ejemplo, la iluminación o las vistas del mismo), y estéticos (por ejemplo, la belleza del edificio) donde el habitante o visitante se encuentre a gusto. Como resultado, se crea una nueva estructura que surge de estos espacios mediante la fusión de lo terapéutico y lo estético. Según Fauconnier and Turner 2002, este proceso conlleva la creación de una red de doble alcance o "double scope network". Esto significa que la distinta procedencia de los entrecruzamientos pueden contribuir de manera uniforme a su integración, lo que ciertamente resulta un fenómeno innovador (Fauconnier and Turner 2002:132). En la ingeniería, el bienestar de las personas que viven en un edificio se relaciona con sentirse cómodo en su interior, recibiendo la cantidad correcta de luz, disfrutando de una vista agradable, la ausencia de ruido molesto, la temperatura y la ventilación. Al mismo tiempo, también lleva implícito que la edificación que presente una forma externa agradable, como resultado de un diseño previo adecuado, tal como representa la figura 2.

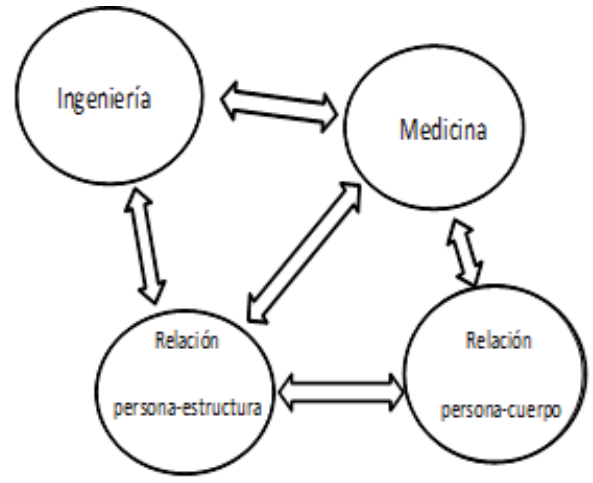

Figura 1: Espacios mentales de aspectos médicos e ingenieriles 


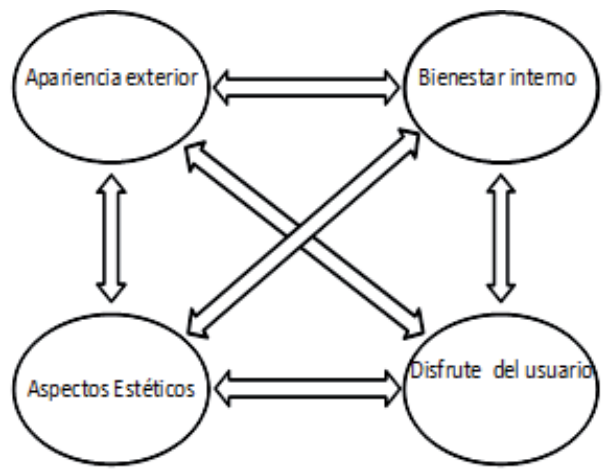

Figura 2: Integración conceptual del ámbito médico y estético

Dada la importancia del diseño en el aspecto exterior de un edificio, el componente visual merece consideración aparte en la ingeniería. Para este propósito hemos optado por un análisis multimodal. Kress (2010:77-78) afirma por ejemplo que sería inexacto estudiar sólo el habla y la escritura para analizar la comunicación humana. En concreto, cuando se refiere a comunicación en el aula propone añadir factores sociales, semióticos y multimodales (por ejemplo, la entonación, los gestos, las imágenes y la acción) que van unidos también al lenguaje. Kress propone analizar el dinamismo y la complejidad de la comunicación humana a través del estudio de "conjuntos multimodales" (Ibíd. p. 81). Del mismo modo, Forceville (2010: 58) argumenta a favor de la conveniencia "de no investigar sólo lo verbal, sino también los tropos no verbales y multimodales" en lo que se refiere a la educación. Tanto Kress como Forceville señalan la "multimodalidad" del significado y de modo particular, la función de la relevancia semiótica para producir significado. Por tanto, la construcción del significado no se limita sólo a elementos lingüísticos, sino que también necesita otros canales como el visual, y por tanto requiere el uso de una variedad de capacidades cognitivas. Este concepto de multimodalidad cobra sentido en el enfoque de la ingeniería, donde muchos ejemplos de metáfora lingüística se desencadenan a partir de estímulos visuales (Caballero 2003a y 2003b, Roldán y Úbeda 2006)

En la ingeniería civil, es posible que el diseñador de un puente quiera representar varias imágenes en la propia forma del puente. En este sentido, tanto el uso práctico del puente como su valor icono-artístico se pueden considerar objetivos de la ingeniería. Por ejemplo, Santiago Calatrava, ingeniero y arquitecto, ha declarado que él designa y elabora su obra como si se tratara de artefactos y esculturas. En el caso del Puente del Alamillo, diseñado como pórtico de la Exposición Universal de Sevilla de 1992, suele ser percibido por los sevillanos como un arpa, un abanico o un cisne que se desliza sobre el río Guadalquivir. Por tanto, aparte de su uso básico como puente que sirve para cruzar un río, la interpretación icónica de sus usuarios depende de relaciones conceptuales de representación, analogía e intencionalidad. La metáfora visual puede estar entonces influida por el contexto de la misma manera que la temática general influye en el tipo de metáfora conceptual (Kövecses 2005).

Si se analiza la asociación de un puente con un cisne, el resultado de las relaciones conceptuales activadas podrían abarcar relaciones de analogía / similitud, de rol-valor y de causaefecto que desembocan en la visión del puente como cisne, combinando la compresión analógica del puente como ave acuática. A su vez, esta conceptualización se mezcla con la 
integración estética de la belleza / elegancia de un cisne, que metonímicamente representa la belleza / y la elegancia del puente. La correspondencia de esta integración es icónica porque la forma (cisne) es un reflejo del significado (puente). También refleja la intencionalidad de su diseño con la conversión de la forma del puente en un símbolo. Cuando se asocia el puente con un arpa, existen también otros efectos comprimidos, como el sonido musical del movimiento del agua. El mapa conceptual del puente como abanico evoca elementos folclóricos locales relacionados con la ciudad meridional de Sevilla, que se añaden a la compresión del mismo. Calatrava ha reconocido que diseñó este puente estableciendo precisamente un diálogo entre su tablero y su original pilar de sujeción o mástil.

En resumidas cuentas, hemos considerado idóneo para completar el estudio que aquí se expone basarnos en algunos de los principios de la teoría de la metáfora conceptual, para pasar a continuación a profundizar en la teoría de integración conceptual y al mismo tiempo explorar el análisis multimodal.

\section{Metodología}

Empíricamente, este trabajo se centra en las respuestas verbales dadas por un grupo de estudiantes de ingeniería civil de Inglés en el $4^{\circ}$ año de sus estudios (de un total de seis años para obtener el título de ingeniero) de la Universidad Politécnica de Madrid. Las respuestas fueron directamente obtenidas después de ver una serie de imágenes de ingeniería. El título de ingeniero civil incluye la asignatura de Inglés que se aprende partiendo de un enfoque IPA (Inglés Profesional y Académico). El nivel de inglés de la mayoría de los estudiantes equivaldría a un nivel B1 o B2 de acuerdo con el baremo establecido por el Marco Europeo de Referencia. Las fotos seleccionadas pertenecen a tres puentes distintos y se les pidió a los participantes que escribieran una palabra que mejor expresara su percepción de cada imagen. Los objetivos inmediatos que se pretendían conseguir era triples, en primer lugar, analizar las conceptualizaciones creadas por los alumnos, en segundo lugar, identificar el uso de la metáfora y en tercer lugar, comparar sus respuestas con las obtenidas de un grupo de 10 ingenieros civiles. Respecto a esto último, sólo hubo una diferencia en el procedimiento seguido para ambos grupos, a saber, que los alumnos respondieron al cuestionario en el aula o por correo electrónico y a los ingenieros se les ofreció acceso a través de Monkey Survey, por razones operativas. En la información proporcionada, a todos los participantes se les pedía transmitir sus primeras impresiones acerca de las fotografías, preferentemente utilizando una sola palabra (aunque algunos participantes utilizaron dos). Las razones para solicitar esto respondían a un intento de recopilar las percepciones más inmediatas de los encuestados. No se incluían otras indicaciones adicionales en la pregunta a fin de no influir o contaminar las respuestas. Por tanto, no se hacía mención alguna sobre metáfora. Los puentes elegidos para la encuesta eran contemporáneos y representativos de la época actual, pero existen otros muchos de esta índole que podían haber sido seleccionados. Concretamente corresponden a: (1) "Príncipe de Viana" puente en Lérida (España, 2010), (2) Puente del Milenio en Newcastle (Reino Unido, 2000), y (3) Ponte do Millenio de Orense (España, 2001). Las fotos están incluidas en los Apéndices finales. Asimismo, para verificar una posible relación entre el uso de la metáfora y la experiencia profesional, se añadieron unas cuantas preguntas preliminares para obtener información adicional sobre los antecedentes de los participantes y su grado de especialización. Las preguntas también se reproducen en el apéndice del documento. 


\section{La metodología se desarrolló en dos etapas principales}

I. El punto de partida procede de varios estudios precedentes de las autoras sobre metáfora (conceptual y lingüística) en la arquitectura y el lenguaje de la ingeniería civil, (Úbeda 2001; Roldán 2004, Roldán and Úbeda 2006; Roldán et al. 2011). Además de los datos recopilados y extraídos de un corpus lingüístico en español e inglés de revistas de ingeniería electrónicas y que abarca un período de 5 años. La aplicación del corpus se realizó utilizando el software (ANTCORD), de ahí se obtuvo una lista de tokens léxicos ordenados de acuerdo a la frecuencia en la que aparecían (adjetivos, verbos y adverbios fueron descartados para centrarse en los nombres). A continuación, las metáforas lingüísticas se identificaron manualmente siguiendo el método propuesto por Steen (1999: 57) y por el grupo Pragglejaz 2007 y posteriormente se utilizaron fichas que se fueron contextualizando mediante el uso de concordancias. La Tabla 1 incluye ejemplos de las metáforas lingüísticas más frecuentes extraídas de este corpus en español.

\begin{tabular}{|l|}
\hline Estado \\
\hline Comportamiento \\
\hline Vida \\
\hline Tratamiento \\
\hline Envejecimiento \\
\hline Auscultación \\
\hline Cabeza \\
\hline Pie \\
\hline
\end{tabular}

Tabla 1: Tokens metafóricos del corpus español ordenado por frecuencia

Es destacable la frecuencia de los significados básicos de muchos de estos tokens en el discurso de ingeniería civil que evocan partes del cuerpo humano (cabeza, pie), procesos que afectan al cuerpo humano (comportamiento, vida, envejecimiento) o presentan contenido médico (tratamiento, auscultación). En cuanto a las concordancias halladas del token "tratamiento", muchas de ellas se colocan con otros términos que llevan una carga adicional metafórica, como "envejecimiento" y "diagnóstico". En conjunto, estos datos apuntan analogías que son habituales y que reflejan la forma en que los ingenieros conciben su trabajo. Casos donde la personificación de la obra se observa de forma directa son el rascacielos llamado "Turning Torso", edificio de altura en Malmö (Suecia) que se inspiró en el cuerpo humano en movimiento. Asimismo, la apertura y cierre del puente movible "Winking eye" de Newcastle (Reino Unido) recuerda el parpadeo o guiño de los ojos. Parece lógico concluir que en muchas realizaciones de ingeniería la analogía está presente y sería interesante explorar el uso de la metáfora en diversas formas: verbal, escrita o visual (Ungerer and Schmidt 2006: 147). Este razonamiento nos condujo a la siguiente etapa del estudio.

II. De hecho, las metáforas en ingeniería se expresan en términos léxicos que suelen evocar una fuente visual. Los ingenieros tienen que recurrir a dibujos y bocetos, no sólo durante la etapa de diseño de los edificios y objetos, sino en todo el proceso de construcción. Una vez que el trabajo se ha terminado, este tiende a sugerir imágenes metafóricas visuales. 
Manterola, ingeniero civil español, asemeja la creación de un puente a la colocación de una cinta para que cubra el suelo o río (Manterola 2010:57):

Lo ideal sería como si despegásemos una tira del suelo de su soporte para pasar el obstáculo. La cinta que es la carretera se separa del suelo para circular a velocidad, y, en esa separación, el río o el valle impiden la progresión de la cinta.

Los proyectos de ingeniería se pueden representar a través de un lenguaje metafórico y en este punto, hacemos la distinción entre metáfora específica y no específica, ya que ambas fueron usadas en los datos obtenidos en este estudio. Por metáfora no específica entendemos la metáfora genérica, es decir, no perteneciente a un dominio en particular. Por ejemplo, "boca de pescado", usada por un estudiante para describir un puente constituye una metáfora no específica. Por el contrario, una metáfora es específica si está relacionada con un área de especialización y es compartida por una comunidad discursiva. Según el grupo Pragglejaz (2007:3), el procedimiento para identificar las palabras individuales de significado metafórico sería la siguiente: "para cada unidad léxica, determinar si tiene un significado contemporáneo más básico en otros contextos del que presenta en un contexto dado". Otro de los principios del grupo Pragglejaz es que los "significados básicos tienden a ser más concretos, y por tanto lo que se evoca es más fácil de imaginar, ver, oír, sentir, oler y gustar, y está más relacionado con la acción corporal, es más preciso, y es históricamente más antiguo" (Ib.). Por tanto, el significado contextual debe ser confrontado con el significado básico: "El significado contextual contrasta pues con ese significado básico y debe ser entendido en relación a ello" (Ibíd. 6). Hemos seguido el método propuesto por este grupo para identificar las metáforas usadas por los participantes de este estudio.

\section{Resultados y discusión}

La tabla 2 contiene siete categorías que se establecieron para clasificar las respuestas entregadas por los participantes en diversos constructos. Estos han sido agrupados de acuerdo con su función gramatical. Por ejemplo: SG (Sustantivo general), es decir, cuando los participantes usaron un sustantivo abstracto no técnico. SAS (Sustantivo área específica) y AAS (Adjetivo de área específica) cuando los participantes reproducen un sustantivo o un adjetivo claramente relacionado con su área de especialización. Del mismo modo, SS (Sustantivo subjetivo) y AS (Adjetivo subjetivo) si los encuestados proporcionaron nombres subjetivos o evaluativos o adjetivos que podrían ser catalogados como una opinión meramente individual. Por último, Mf. (metáfora), la metáfora, utilizada para reflejar el uso de la metáfora de cualquier tipo y Mn. para la (metonimia). 


\begin{tabular}{|l|l|}
\hline SG: & Sustantivo general \\
\hline SAS: & Sustantivo área es pecífica \\
\hline AAS: & Adjetivo área es pecífica \\
\hline SS: & Sus tantivo subj etivo \\
\hline AS: & Adjetivo subj etivo \\
\hline Mf: & Metáfora \\
\hline Mn: & Metonimia \\
\hline
\end{tabular}

Tabla 2: Tipos de constructos

Esta clasificación responde principalmente a razones de orden práctico, ya que cualquiera de las respuestas, incluso las consideradas subjetivas, podría estar influida de alguna manera por el área de conocimiento. A continuación en la tabla 3, se incluyen ejemplos de las respuestas de los estudiantes y de los ingenieros distribuidas en dos columnas y ordenadas de acuerdo con el tipo de constructos.

\begin{tabular}{|c|c|c|}
\hline Categorías & $\begin{array}{c}\text { Estudiantes de } \\
\text { Ingeniería }\end{array}$ & Ingenieros \\
\hline SG & estética & belleza \\
\hline SAS & tirante & pasarela \\
\hline AAS & estable & atirantado \\
\hline SS & complicación & ficción \\
\hline AS & curioso & innecesario \\
\hline Mf & ojo & ADN \\
\hline Mn & cinta de moebius & arco \\
\hline
\end{tabular}

Tabla 3: Ejemplos de constructos por grupos

Las tablas 3a y 3 b ofrecen los datos obtenidos según el porcentaje de constructos anteriormente mencionados. 


\begin{tabular}{|l|c|c|}
\hline \multirow{2}{*}{} & \multicolumn{2}{|c|}{ Estudiantes de ingenieria } \\
\cline { 2 - 3 } & Frecuencia & porcentaje \\
\hline SG & 5 & $8 \%$ \\
\hline SAS & 7 & $11 \%$ \\
\hline AAS & 12 & $19 \%$ \\
\hline SS & 7 & $11 \%$ \\
\hline AS & 16 & $26 \%$ \\
\hline Mf & 11 & $18 \%$ \\
\hline Mn & 4 & $7 \%$ \\
\hline
\end{tabular}

Tabla 3.a Frecuencia de las categorias y su porcentaje

\begin{tabular}{|l|c|c|}
\hline \multirow{2}{*}{} & \multicolumn{2}{|c|}{ ingenieros } \\
\cline { 2 - 3 } & Frecuencia & Porcentaje \\
\hline SG & 3 & $8 \%$ \\
\hline SAS & 3 & $8 \%$ \\
\hline AAS & 6 & $15 \%$ \\
\hline SS & 9 & $23 \%$ \\
\hline AS & 10 & $26 \%$ \\
\hline Mf & 4 & $10 \%$ \\
\hline Mn & 4 & $10 \%$ \\
\hline
\end{tabular}

Tabla 3.b Frecuencia de las categorias y su porcentaje

Los resultados revelan un importante número de adjetivos subjetivos (AS) utilizados por los estudiantes (26\%), que coincide con una frecuencia similar para el grupo de ingenieros (26\%), este último también refleja un alto porcentaje de uso (23\%) de los sustantivos subjetivos (SS) y un número significativo de adjetivos de área específica (AAS) (15\%). Probablemente, esto se pueda atribuir al hecho de que los ingenieros están habituados a emitir informes técnicos que contienen dictámenes de evaluación o peritaje. El uso de la metáfora es notable en el caso de los estudiantes (18\%). Este hecho se analiza a continuación.

Las metáforas aparecen clasificadas en la tabla 4 atendiendo a su contenido temático. Previamente se había procedido a identificarlas de acuerdo con las indicaciones del grupo Pragglejaz (2007:3). En concreto, el grupo 1 se refiere a la noción de "forma", ya que la mayoría de los ejemplos refieren una variedad de ellas. Este primer grupo se dividió más abajo en dos subgrupos. El subgrupo 1.1 incluye metáforas que podrían ser consideradas convencionalmente como típicas de la ingeniería civil. Es decir, son frecuentes en el lenguaje técnico de ingeniería. Por el contrario, el subgrupo 1.2, al tiempo que hacen alusión a la forma, incluyen también metáforas no específicas, es decir metáforas genéricas de carácter no técnico. El Diccionario online DRAE se utilizó para comprobar los significados básicos de los casos incluidos. 


\begin{tabular}{|l|l|l|l|}
\hline \multicolumn{2}{|c|}{ Tipo de metáfora } & $\begin{array}{l}\text { Estudiantes de } \\
\text { ingeniería }\end{array}$ & \multicolumn{1}{|c|}{ Ingenieros } \\
\hline \multirow{2}{*}{ 1. Forma } & 1.1 específica & $\begin{array}{l}\text { abanico } \\
\text { arpa }\end{array}$ & arpa \\
\cline { 2 - 4 } & 1.2 no específica & $\begin{array}{l}\text { mariposa } \\
\text { silla de montar } \\
\text { boca de pez } \\
\text { velero ojo } \\
\text { abanico }\end{array}$ & mandíbulas \\
\hline 2. Otras disciplinas & $\begin{array}{l}\text { ciencia } \\
\text { tecología }\end{array}$ & ADN \\
\hline 3. Otros & & McDonald's \\
\hline
\end{tabular}

Tabla 4: Metáforas agrupadas por temática

Analizando los ejemplos, en el caso de la metáfora de McDonald, que podría tener un significado despectivo, y de donde se podría deducir la analogía de la construcción de puentes sin una base sólida o un cuidado proceso técnico, con la de una cadena de producción de alimentos rápidos. El significado contextual contrasta con el significado básico y se puede deducir al comparar ambos, cuestionando así las condiciones básicas del puente. Además, el constructo McDonald puede conllevar implicaciones metafóricas de consumo inmediato sin pensar en riesgos a medio y largo plazo, lo que traducido al puente se referiría a su mantenimiento posterior.

\begin{tabular}{|l|c|c|}
\hline & \multicolumn{2}{|c|}{ Estudiantes de Ingenieria } \\
\cline { 2 - 3 } & Frecuencia & Porcentaje \\
\hline $\begin{array}{l}\text { Forma metaf. } \\
\text { convencional }\end{array}$ & 3 & $25 \%$ \\
\hline $\begin{array}{l}\text { Forma metaf. no } \\
\text { convencional }\end{array}$ & 6 & $50 \%$ \\
\hline Otras disciplinas & 3 & $25 \%$ \\
\hline Otros & 0 & $0 \%$ \\
\hline
\end{tabular}

Tabla 5.a Frecuencia de metaforas y porcentaje por grupo de estudientes

\begin{tabular}{|l|c|c|}
\hline \multirow{2}{*}{} & \multicolumn{2}{|c|}{ Ingenieros } \\
\cline { 2 - 3 } & Frecuencia & Porcentaje \\
\hline $\begin{array}{l}\text { Forma metaf } \\
\text { corrvencional }\end{array}$ & 2 & $40 \%$ \\
\hline $\begin{array}{l}\text { Forma metaf no } \\
\text { corrvencional }\end{array}$ & 1 & $20 \%$ \\
\hline Otras disciplinas & 1 & $20 \%$ \\
\hline Otros & 1 & $20 \%$ \\
\hline
\end{tabular}

Tabla 5.b Frecuencia de metaforas y porcentaje por grupo de profesionales

En las tablas 5.a y 5.b se muestran los porcentajes de uso de la metáfora distribuidos por grupos. Las metáforas relacionadas con la forma aparecen en un alto porcentaje en ambos grupos. Sin embargo, mientras que los ingenieros utilizan una cantidad más alta de metáfora de área específica (40\%), los estudiantes usan generalmente las no específicas (50\%). Este fenómeno muestra que el uso de la metáfora presenta un carácter progresivo en las diferentes etapas de ingeniería, académica y profesional.

De vez en cuando nos encontramos con que la metáfora y la metonimia co-existen en la misma figura de discurso y se podría interpretar como una u otra. De hecho, la metáfora y la metonimia, aunque muy diferentes en su mecanismo, pueden aparecer juntas en un continuo donde llegan a ser difíciles de disociar. Este fenómeno ha sido denominado como "meta- 
phonymy" (Goossens, 1995:160). Por ejemplo, se usan dos constructos en concreto con la relación metonímica "la forma por el todo" mostrando una fuerte asociación visual con formas geométricas como se observa en la figura 4. Al mismo tiempo, resulta ser igualmente metafórico (ADN y puente), reflejando personificación y analogía geométrica simultáneamente. Las imágenes superiores muestran una analogía entre la representación del ADN y la forma de Ponte do Milenio y las inferiores representan la cinta de Möebius (un tipo especial de cilindro y objeto matemático) evocadas por el Puente del Milenio de Gateshead.

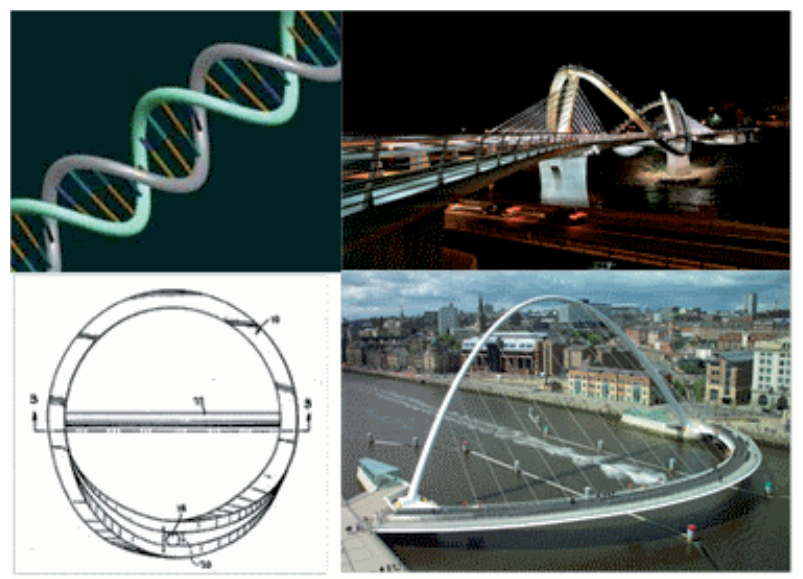

Figura 3: Asociaciones Metonímicas y Metafóricas Extraídas de la Muestra

La principal diferencia entre metonimia y metáfora radica en que la metonimia no "transfiere" su significado en una relación de semejanza, sino que combina los significados en el mismo dominio. Esta relación puede ser la parte por el todo, efecto por la causa. Se puede decir que la metonimia crea contigüidad entre dos conceptos, mientras que la metáfora funciona mediante el establecimiento de una comparación entre ellos. Según el Grupo Pragglejaz 2007, la metáfora básicamente se ocupa de la comparación, mientras que la metonimia expresaría "un sustituto de, o la parte por el todo, la relación que se diferencia de los procesos de comparación". En conclusión, los resultados indican que los estudiantes aún no han alcanzado un grado de familiarización con el uso de la metáfora o la metonimia de su especialidad y que su uso de la metáfora podría ser intuitivo. Por ello consideramos que la inclusión de la metáfora dentro del programa académico podría hacer que los estudiantes fuesen más conscientes de la importancia de esta herramienta de la lengua dentro de su propia comunidad discursiva.

\section{Conclusiones}

En este trabajo, se ha intentado examinar los usos de la metáfora en el ámbito de la ingeniería civil Como una extensión de su uso en este campo, los aspectos conceptuales, lingüísticos y visual se han tenido en cuenta tanto en la etapa académica como en la profesional. El objetivo específico de este estudio se ha centrado en realizar un análisis en profundidad de las conceptualizaciones y constructos de un grupo de estudiantes de ingeniería y un grupo de ingenieros para describir ejemplos visuales de su especialidad. Con este fin, 
se han presentado algunas ideas acerca de la manera en que los ingenieros suelen interpretar y transmitir imágenes en su área de especialidad. En el análisis de los resultados, se ha constatado la presencia de la metáfora, sobre todo la metáfora asociada visualmente a distintas formas, en la vertiente técnica o específica como en la general o no específica, dependiendo del grado de familiaridad académico o profesional.

En cuanto a las restricciones del estudio, mencionamos que la aplicabilidad del mismo se puede ver en parte limitada por cierto grado de subjetividad de los resultados, en función del diseño del cuestionario. No obstante, destacamos que son necesarios estudios de esta índole para discernir el grado y nivel de percepción metafórica de los estudiantes, puesto que dada la interrelación de las materias que componen los estudios, el uso de la metáfora es extensible a muchas de ellas. Entre las líneas de seguimiento de la investigación, partiendo de la ubicuidad de la metáfora visual en la ingeniería civil, se recomienda la aplicación del enfoque multimodal que integre el uso de imágenes metafóricas dentro y fuera del aula. Este trabajo podría plasmarse a través de la recogida y estructuración de ejemplos auténticos de metáfora lingüística, conceptual y visual, ampliando el estudio a aspectos paralingüísticos y socio-cognitivos propios de la etapa ocupacional, mediante la utilización de datos compilados en forma de corpora y banco de imágenes. Por ello, indicamos la utilidad de incluir en los programas curriculares de ingeniería el estudio del uso multimodal de la metáfora en el plano comunicativo, al menos como asignatura transversal, para que los alumnos se familiaricen con su uso y sean conscientes del papel que juega en el contexto de la ingeniería. A este respecto, consideramos que a partir del tercer año de carrera y contando con el aprendizaje adecuado, los alumnos serían capaces de calibrar la presencia y el uso de la metáfora en las distintas asignaturas, en forma verbal y conceptual, así como en imágenes. Esperamos, finalmente, que a partir de aquí surjan otros estudios que profundicen en posibles actividades pedagógicas que aborden el uso de la metáfora en todas las ramas de la ingeniería y en la arquitectura. 


\section{Referencias}

Arnheim, R. (1969). Visual Thinking . Berkeley and Los Angeles, University of California Press.

Caballero, R. (2003a). "Talking about space: image metaphor in architectural discourse". .Annual Review of Cognitive Linguistics 1, 89-108.

Caballero, R. (2003b). "Metaphor and genre: the presence and role of metaphor in the blending review". Applied Linguistics 24/2: 145-167.

Caballero R. y Pinar M. J. (Eds.) (2010). Modos y Formas de la Comunicación Humana / Ways and Modes of Human Communication. Ediciones de la Universidad de Castilla La Mancha.

Cameron, L. "What is metaphor and why does it matter". On-line PowerPoint presentation: http://creet.open.ac.uk/projects/metaphor-analysis/frame.htm (consultado el 10 de enero 2012).

Cameron, L. and Low, G. (Eds.) (1999). Researching and Applying Metaphor. Cambridge: Cambridge University Press.

Cortazzi, M. . and Jin, L. (1999). "Bridges to Learning: Metaphors of teaching, learning and language", in Cameron L. and Low G. (eds.). Researching and Applying Metaphor, pp: 149-177.

Deignan, A. (2005). Metaphor and Corpus Linguistics. Amsterdam/Philadelphia: John Benjamins Publishing Company. Cognitive perspectives on SLA.

Diccionario de la Lengua Española (DRAE). Vigésimo segunda edición. On-line: http://lema.rae.es/drae/ (consultado el 30 de septiembre 2011).

Fauconnier G. and Turner, M. (2008). 'Rethinking Metaphor'. in Gibbs, R. (ed.) Cambridge Handbook of Metaphor and Thought. Cambridge University Press. También disponible en: http://www.cogsci.ucsd.edu/ faucon/RethinkingMetaphor19f06.pdf (consultado el 19 de julio 2011).

Fauconnier, G. (1997). Mappings in thought and language. Cambridge: Cambridge University Press.

Fauconnier, G. and Turner, M. (2002). The Way We Think: Conceptual Blending and the Mind's Hidden Complexities. New York: Basic Books.

Fauconnier, G. http://terpconnect.umd.edu/ israel/Fauconnier-MentalSpaces.pdf. (consultado el 26 de junio de 2011).

Forceville, Ch. (2010). "Why and how study metaphor, metonymy, and other tropes in multimodal discourse", in Caballero R. y Pinar M.J. (eds.). Ways and Modes of Human Communication. Cuenca: Ed. Universidad Castilla-La Mancha, pp.: 57-77.

Goossens, L. (1995). "Metaphtonymy: the interaction of metaphor and metonymy in figurative expressions for linguistic action", in Goossens L., Pauwels,P., Rudzka-Ostyn B., Simon-Vandenbergen A.M. and Vanparys J. (eds.), By Word of Mouth: Metaphor, Metonymy and Linguistic Action in a Cognitive Perspective. Amsterdam/Philadelphia: John Benjamins, pp. 160-174.

Grady, J., Oakley, T., and Coulson, S. (1999) “Blending and Metaphor”, in R. Gibbs and G. Steen (eds.). Metaphor in Cognitive Linguistics. Philadelphia: John Benjamins.

Kövecses, Z. (2005). Metaphor in Culture: Universality and Variation. Cambridge: Cambridge University Press.

Kress, G. (2010). "A social semiotic approach to human communication: implications for speech, writing and applied linguistics", in Caballero y Pinar (eds.), Ways and Modes of Human Communication. Cuenca: Ed. Universidad Castilla-La Mancha, pp.: 77-93.

Lakoff, G. (1987). Women, fire, and dangerous things: What categories reveal about the mind. Chicago: University of Chicago.

Littlemore, J. (2009). Applying Cognitive Linguistics to Second Language Learning and Teaching. Basingstoke: Palgrave MacMillan.

Littlemore, J. and Low, G. (2006). Figurative Thinking and Foreign Language Learning. New York: Palgrave Macmillan.

Low, G. (1999). “This paper thinks...” Investigating the acceptability of the metaphor AN ESSAY IS A PERSON". in Cameron, L. and Low, G. (eds.), pp. 221-249. 
Manterola, J. (2010). La obra de ingeniería como obra de arte. Pamplona: Ed. Laetoli.

Pragglejaz Group. (2007). "MIP: A method for identifying metaphorically used words in discourse". Metaphor and Symbol 22: 1-39.

Robisco Martín, M. (2009). Análisis cognitivo de las preposiciones en torno al eje de verticalidad en el inglés para la Aeronáutica. Tesis doctoral inédita. Madrid Universidad Politécnica.

Roldán Riejos, A. (1999). "Applications of cognitive theory to interdisciplinary work in Languages for Specific Purposes". Ibérica. Vol.: 1: 29-37. Madrid.

Roldán Riejos, A.; Úbeda, P. and Martín, A. (2001). "The impact of visuals: using a poster to present metaphor". European Journal of Engineering Education. Vol.: 26: 301- 310. London.

Roldán Riejos, A. (2004). "Strategic features of ESP from a socio-cognitive perspective". Ibéric a. Vol.: 7: 33-51. Madrid.

Roldán Riejos, A. and Úbeda Mansilla, P. (2006). "Metaphor use in a specific genre of engineering discourse". European Journal of Engineering Education. Vol. 31.5: 531-541.

Roldán Riejos, A., Úbeda Mansilla, P. and Santiago Lopez, J. (2011) The Language of Architecture and Civil Engineering. Newcastle: Cambridge Scholars Publisher.

Steen, G.J. (1999). "From linguistic to conceptual metaphor in five steps", in Gibbs, R. and G. Steen (eds.): Metaphor in Cognitive Linguistics.: 57-71. Amsterdam: John Benjamins.

Steen, G. J. (2007). Finding Metaphor in Grammar and Usage. Amsterdam: John Benjamins Publishing. Úbeda Mansilla, P. (2001): Estudio de un corpus de textos conversacionales en inglés realizados en estudios de arquitectura de habla inglesa: su aplicación al diseño de un curso de inglés para arquitectos. Tesis doctoral. Madrid: Universidad Complutense de Madrid.

Úbeda Mansilla, P. (2002). "Metaphor at work: a study of metaphors used by European architects when talking about their projects". I bérica. Vol. 5: 35-48.

Ungerer, F. and Schmidt, H.-J. (2006). An Introduction to Cognitive Linguistics. London: Longman.

\section{Anexo 1: El cuestionario}

\section{DEPARTAMENTO DE LINGÜÍSTICA APLICADA A LA CIENCIA Y A LA TECNOLOGÍA. ETSI CAMINOS, CANALES Y PUERTOS}

\section{UNIVERSIDAD POLITÉCNICA DE MADRID (UPM)}

Este cuestionario forma parte de un trabajo de investigación que se está llevando a cabo sobre formas de conocimiento y la construcción del significado en el ámbito académico y profesional. Los resultados serán tenidos en cuenta para el diseño de un estudio más amplio coordinado en la Universidad Politécnica de Madrid.

El principal objetivo es obtener información sobre técnicas de percepción y comprensión, partiendo de varios ejemplos.

Por favor, responde a cada pregunta rellenando las casillas o escribiendo una respuesta, según el caso. Recuerda que la información proporcionada será confidencial y que tiene una finalidad exclusivamente científica.

¡Muchas gracias por tu participación!

Cuando hayas terminado de contestar el cuestionario, por favor, envíalo a la dirección de correo electrónico que se indica: 
Profs. Ana Roldán-Riejos y Paloma Úbeda Mansilla

Departamento de Lingüística Aplicada a la Ciencia y Tecnología

ETSI de Caminos, Canales y Puertos. C/ Prof. Aranguren s/n. Madrid 28040. SPAIN

E-MAIL ADDRESS: aroldan@caminos.upm.es

Indica si eres: $\square$ Hombre $\square$ Mujer

Señala la franja de edad a la que perteneces: $35-40 \square \quad 41-45 \square \quad 46-50 \square \quad 51-55 \square \quad 56-65 \square$

1.1. ¿Eres Ingeniero? $\square \mathrm{S}$ í $\square$ No

1.2. Cuál es tu campo de trabajo:

2.1. Al planteart e el diseño de un puente u otro tipo de obra, numerar de 1 a 5 el papel desempeñado por los siguientes elementos (5 importancia mayor; 1 menor.):

\begin{tabular}{|l|l|l|l|l|l|}
\hline & -1 & 2 & 3 & 4 & $5+$ \\
\hline Su forma global & & & & & \\
\hline Los cimientos y cada elemento por separado & & & & & \\
\hline Su estabilidad futura & & & & & \\
\hline Su integración en el medio & & & & & \\
\hline Otros (por favor especificar): & \multicolumn{5}{|l}{} \\
\hline
\end{tabular}

2.2. Cuando proyecta s cualquier tipo de estructura, dedicas una atención principal a: (por favor numerar por orden de importancia, 5 importancia mayor, 1 menor):

\begin{tabular}{|l|l|l|l|l|l|}
\hline & -1 & 2 & 3 & 4 & $5+$ \\
\hline Su apariencia estética & & & & & \\
\hline Los cálculos de diseño y ejecución & & & & & \\
\hline Su evolución & & & & & \\
\hline Su coste & & & & & \\
\hline Otros (por favor especificar): & \multicolumn{5}{|l}{} \\
\hline
\end{tabular}


2.3. Al hablar con un colega de cualquier estructura, tiendes a: (por favor numerar por orden de importancia, 5 importancia mayor, 1 menor)

\begin{tabular}{|l|l|l|l|l|l|}
\hline & -1 & 2 & 3 & 4 & $5+$ \\
\hline Hacer un dibujo de la misma & & & & & \\
\hline Utilizar un diagrama & & & & & \\
\hline Hacer uso de cálculos matemáticos & & & & & \\
\hline Explicar con palabras & & & & & \\
\hline Otros (por favor especificar): & \multicolumn{5}{|l|}{} \\
\hline
\end{tabular}

2.4. Al leer sobre la construcción de un puente, prestas más atención y tiempo a (por favor numerar por orden de importancia, 5 importancia, mayor, 1 menor):

\begin{tabular}{|l|l|l|l|l|l|}
\hline & -1 & 2 & 3 & 4 & $5+$ \\
\hline Los dibujos, fotografías, diagramas & & & & & \\
\hline Las explicaciones matemáticas & & & & & \\
\hline El texto que acompaña & & & & & \\
\hline Ejemplos similares & & & & & \\
\hline Otros (por favor especificar): & \multicolumn{5}{|l}{} \\
\hline
\end{tabular}

2.5. En la práctica de la ingeniería civil, ¿cuál es el orden de importancia que se suele otorgar a lo siguiente? Por favor numerar por orden de importancia, 5 importancia mayor, 1 menor):

\begin{tabular}{|l|l|l|l|l|l|}
\hline & -1 & 2 & 3 & 4 & $5+$ \\
\hline No sobrepasar el presupuesto & & & & & \\
\hline La durabilidad & & & & & \\
\hline Su apariencia & & & & & \\
\hline Su utilidad & & & & & \\
\hline Otros (por favor, especificar): & \multicolumn{5}{|l}{} \\
\hline
\end{tabular}


2.6. En el desarrollo de tu trabajo ¿qué importancia le das tú personalmente a lo siguiente? (por favor numerar por orden de importancia, 5 importancia mayor, 1 menor):

\begin{tabular}{|l|l|l|l|l|l|}
\hline & -1 & 2 & 3 & 4 & $5+$ \\
\hline No sobrepasar el presupuesto & & & & & \\
\hline La durabilidad & & & & & \\
\hline Su apariencia & & & & & \\
\hline Su utilidad & & & & & \\
\hline Otros (por favor, especificar): & \multicolumn{5}{|l|}{} \\
\hline
\end{tabular}

2.7. Después de mirar las siguientes fotografías, escribe una palabra que mejor ilustre tu percepción de cada una de ellas:

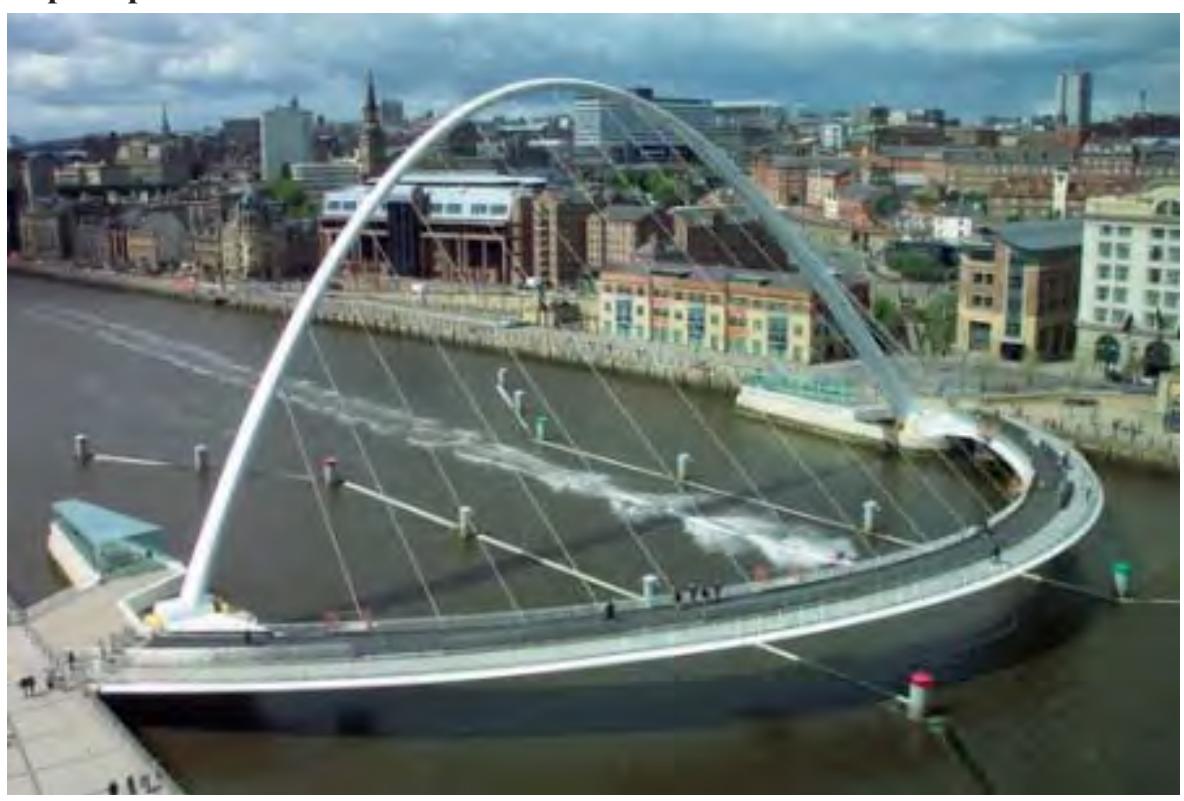

2.7.1. Escribe una palabra que mejor ilustre tu percepción: 


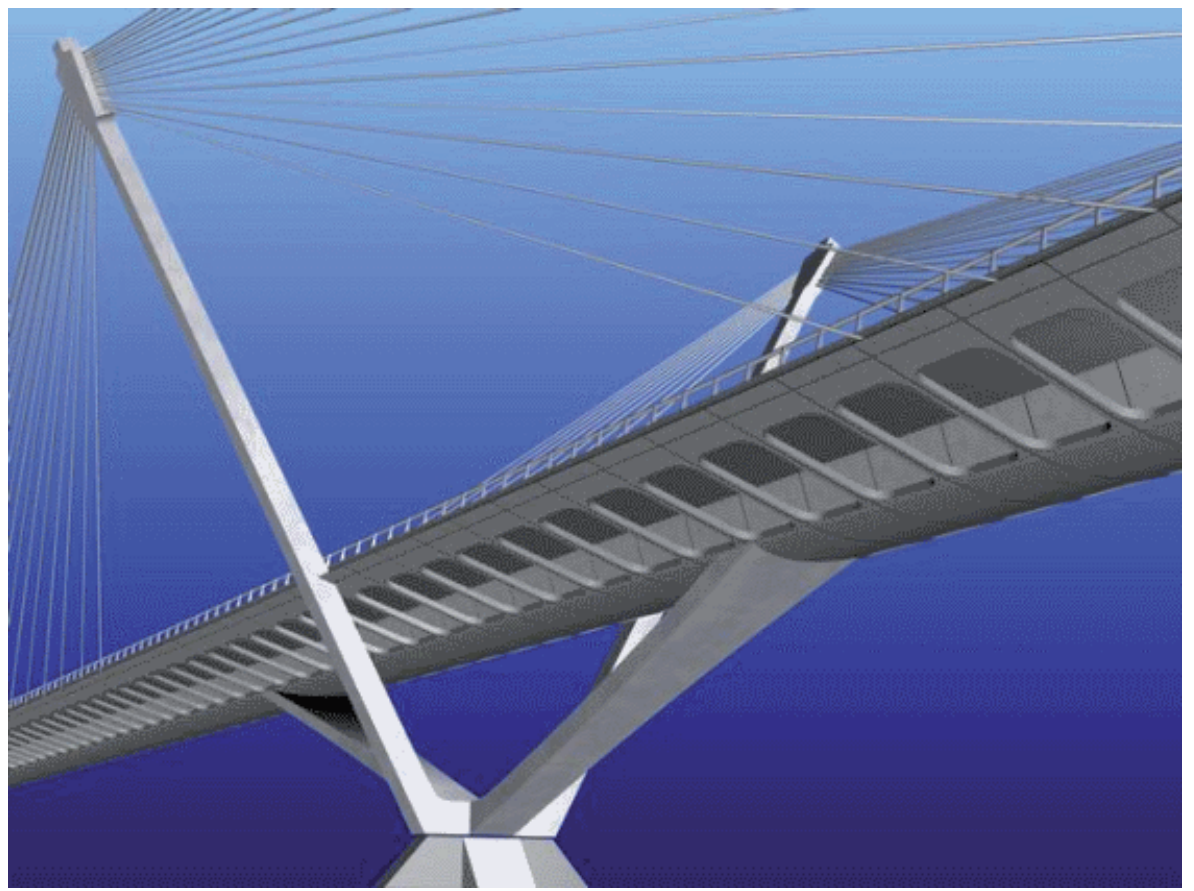

2.7.2. Escribe una palabra que mejor ilustre tu percepción :

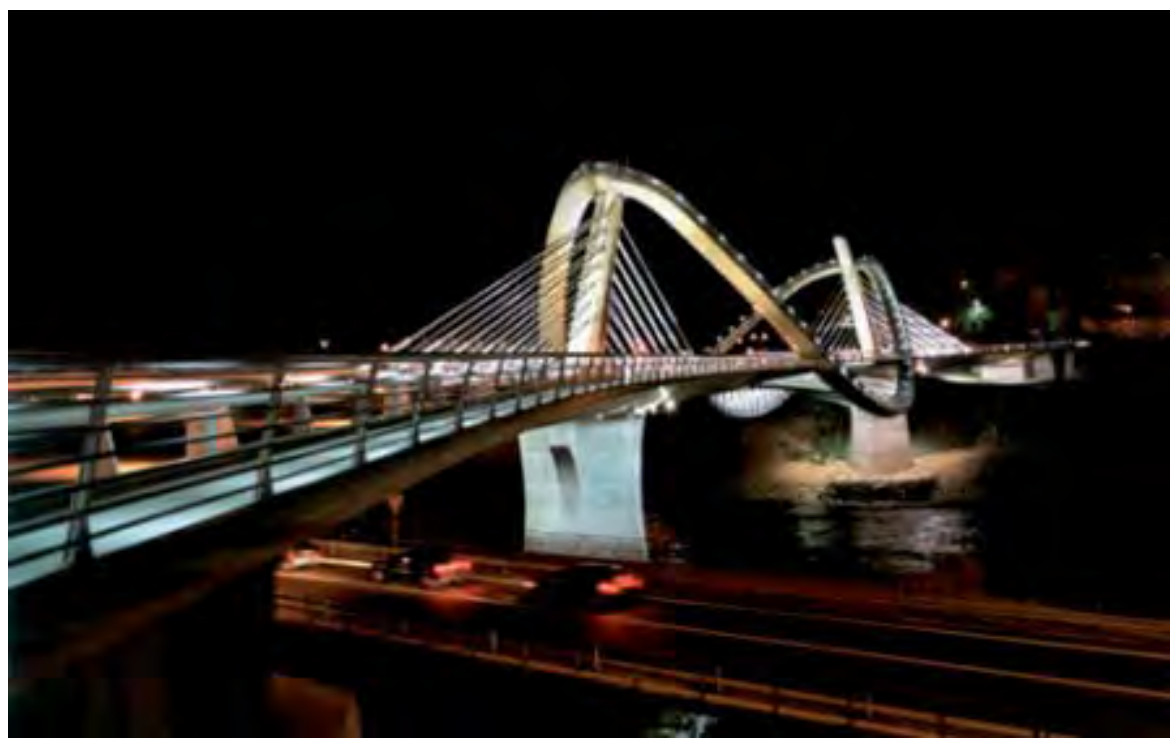

2.7.3. Escribe una palabra que mejor ilustre tu percepción :

Gracias por participar 


\section{Sobre las Autoras}

Dra. Ana Roldán-Riejos: Ana Roldán-Riejos (BA; PhD; Diploma in Translation Studies) is an Associate Professor in UPM (Madrid Technical University) where she teaches English for Specific Purposes (ESP), in particular academic and professional English for engineers, at the Civil Engineering School. She has participated in various university-funded research projects on the influence of tutorials on engineering students and also on special integrated actions between UK and Spanish institutions. The most recent ones, that she coordinates, deal with higher education ELP (European Portfolio of Languages) application in ESP contexts and with a dictionary of technical metaphors. She has published research articles in international journals and presented papers in conferences on Linguistics and on Education for engineers both in Spain and in various European countries. She has supervised various doctoral theses and belongs to the editorial committee of Ibérica AELFE Journal.

Dr. Paloma Úbeda-Mansilla: Paloma Úbeda-Mansilla is a Senior Lecturer in the Department of Linguistic Applied to Science and Technology in the Technical University of Madrid. She has been teaching English and Spanish as a second language for 17 years at different educational levels and lecturing ESP for architects since 1994. She taught Spanish in Exeter (U.K) for two years and in several Secondary Schools in Sweden. She has a PhD in Education with a special mention by the Complutense University of Madrid and a Postgraduate Diploma in TEFL from Exeter University. She also lectures Doctorate and Master courses on Language and Communication subjects. Her research interests include teaching methodology, cognitive linguistics and Professional Application in English and Spanish for Architects. 